\title{
Article
}

\section{Localized Energy Band Bending in ZnO Nanorods Decorated with Au Nanoparticles}

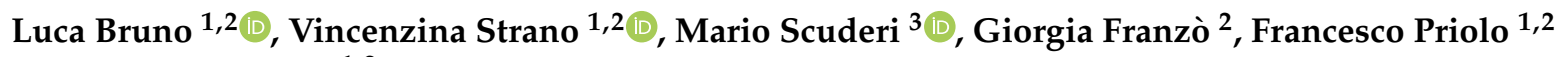 \\ and Salvo Mirabella ${ }^{1,2, *}$ \\ 1 Department of Physics and Astronomy "Ettore Majorana”, University of Catania, Via S. Sofia 64, \\ 95123 Catania, Italy; luca.bruno@dfa.unict.it (L.B.); stravicky@hotmail.it (V.S.); \\ francesco.priolo@ct.infn.it (F.P.) \\ 2 IMM-CNR, Via S. Sofia 64, 95123 Catania, Italy; giorgia.franzo@ct.infn.it \\ 3 IMM-CNR, VIII Strada 5, 95121 Catania, Italy; mario.scuderi@imm.cnr.it \\ * Correspondence: salvo.mirabella@dfa.unict.it
}

check for

updates

Citation: Bruno, L.; Strano, V.;

Scuderi, M.; Franzò, G.; Priolo, F.;

Mirabella, S. Localized Energy Band

Bending in $\mathrm{ZnO}$ Nanorods Decorated

with Au Nanoparticles. Nanomaterials

2021, 11, 2718. https://doi.org/

$10.3390 /$ nano11102718

Academic Editors: José

Ramón Ramos-Barrado and

Gyaneshwar P. Srivastava

Received: 6 September 2021

Accepted: 12 October 2021

Published: 14 October 2021

Publisher's Note: MDPI stays neutral with regard to jurisdictional claims in published maps and institutional affiliations.

Copyright: (c) 2021 by the authors. Licensee MDPI, Basel, Switzerland. This article is an open access article distributed under the terms and conditions of the Creative Commons Attribution (CC BY) license (https:/ / creativecommons.org/licenses/by/ $4.0 /)$.

\begin{abstract}
Surface decoration by means of metal nanostructures is an effective way to locally modify the electronic properties of materials. The decoration of $\mathrm{ZnO}$ nanorods by means of Au nanoparticles was experimentally investigated and modelled in terms of energy band bending. $\mathrm{ZnO}$ nanorods were synthesized by chemical bath deposition. Decoration with Au nanoparticles was achieved by immersion in a colloidal solution obtained through the modified Turkevich method. The surface of $\mathrm{ZnO}$ nanorods was quantitatively investigated by Scanning Electron Microscopy, Transmission Electron Microscopy and Rutherford Backscattering Spectrometry. The Photoluminescence and Cathodoluminescence of bare and decorated $\mathrm{ZnO}$ nanorods were investigated, as well as the band bending through Mott-Schottky electrochemical analyses. Decoration with Au nanoparticles induced a 10 times reduction in free electrons below the surface of $\mathrm{ZnO}$, together with a decrease in UV luminescence and an increase in visible-UV intensity ratio. The effect of decoration was modelled with a nano-Schottky junction at $\mathrm{ZnO}$ surface below the Au nanoparticle with a Multiphysics approach. An extensive electric field with a specific halo effect formed beneath the metal-semiconductor interface. $\mathrm{ZnO}$ nanorod decoration with Au nanoparticles was shown to be a versatile method to tailor the electronic properties at the semiconductor surface.
\end{abstract}

Keywords: Au nanoparticles synthesis; zinc oxide nanorods; decoration; energy bands modification; luminescence; halo effect

\section{Introduction}

Zinc oxide $(\mathrm{ZnO})$ is an $n$-type semiconductor (band gap of 3.2-3.4 eV, large excitonicbinding energy of $60 \mathrm{meV}$ ) attracting great attention due to its physical and chemical properties [1,2]. In particular, $\mathrm{ZnO}$ nanorods (NRs) have proven to be promising nanostructures for a wide range of applications, especially for photonics and optoelectronics in the UV or blue spectral range [3-9]. A controlled improvement of performance needs a microscopic understanding of $\mathrm{ZnO}$ surface states and deep levels, especially in low-dimensional nanostructures where the significant surface-to-bulk ratio significantly impacts electronic energy band bending.

The surface decoration of semiconductor nanostructures with metallic nanoparticles (NPs) usually leads to an improvement of their catalytic and electrical properties [10-14]. The formation of nano-Schottky junctions at the metal-semiconductor interface leads to the creation of a strong electric field directed toward the surface and to a significant modification of the ZnO NRs energy band profiles [15-19]. As a consequence, space charge regions and surface-localized electric fields promote a catalytic effect and modify the radiative recombination process. Apart from near-band-edge emission, $\mathrm{ZnO}$ nanostructures may also exhibit luminescence in the visible range [1,20-27]. When decorated, luminescence 
from $\mathrm{ZnO}$ NRs changes, with an enhancement of visible emission at the expense of UV emission $[10,19,28,29]$. Such a process could be the consequence of a significant bending of electronic energy bands into $\mathrm{ZnO}$ just below the metal nanoparticle, inducing free carrier depletion. Such an effect in decorated $\mathrm{ZnO}$ nanorods allows the application of these composite materials in UV sensing and light-induced catalysis $[11,16,18,19,30,31]$.

In this work, we systematically investigated the decoration of $\mathrm{ZnO}$ NRs with Au NPs and its effect on position and population of electronic energy bands. Photoluminescence and cathodoluminescence were used to exploit the decoration effect to different extents. Energy band modifications and carrier concentrations were also investigated through electrochemical analyses and simulated using a multiphysics approach, revealing a noticeable halo effect in the electric field at the $\mathrm{ZnO}$ surface close to the edges of the Au NPs.

\section{Materials and Methods}

\subsection{Synthesis and Decoration of $\mathrm{ZnO}$ Nanorods}

$\mathrm{ZnO}$ NRs were synthesized through chemical bath deposition (CBD) on Si substrates cut by Czochzralski $(\mathrm{Cz})$ wafers. Zinc nitrate hexahydrate $\left(\mathrm{Zn}\left(\mathrm{NO}_{3}\right)_{2} \cdot 6 \mathrm{H}_{2} \mathrm{O}\right.$, Sigma-Aldrich, St. Louis, MO, USA, $\geq 99 \%$ ) and hexamethylenetetramine (HMTA, Sigma-Aldrich, St. Louis, $\mathrm{MO}, \mathrm{USA}, \geq 99.5 \%$ ) were used for the growth of $\mathrm{ZnO}$ NRs with concentrations of $25 \mathrm{mM}$ and $50 \mathrm{mM}$, respectively [32].

Au NPs were synthesized through the modified Turkevich method [33-35] at room temperature, without any correction of the $\mathrm{pH}$ of the solution (see Supplementary Information). Gold chloride trihydrate $\left(\mathrm{HAuCl}_{4} \cdot 3 \mathrm{H}_{2} \mathrm{O}\right.$, Sigma-Aldrich, St. Louis, MO, USA, $\geq 99.9 \%)$ and trisodium citrate $\left(\mathrm{Na}_{3} \mathrm{C}_{6} \mathrm{H}_{5} \mathrm{O}_{7} \cdot \mathrm{H}_{2} \mathrm{O}\right.$, Sigma-Aldrich, St. Louis, MO, USA) were used without further purification.

ZnO NRs were decorated via dip coating by simply immersing different substrates in the Au NP colloidal solution. Decorated samples are labelled according to the number of immersions in the solution (e.g., $\mathrm{Au}_{5}-\mathrm{ZnO}$ refers to a $\mathrm{ZnO}$ NR immersed 5 times into $\mathrm{Au}$ NP solution).

\subsection{Characterization}

UV-vis spectroscopy was performed on the Au solution using a Varian Cary 500 (Agilent Technologies, Santa Clara, CA, USA) double beam scanning UV/VIS/NIR spectrophotometer.

Surface morphology was analyzed by using a Scanning Electron Microscope (Gemini field emission SEM Carl Zeiss SUPRA 25, FEG-SEM, Carl Zeiss Microscopy GmbH, Jena, Germany). SEM images were analyzed using ImageJ software [36].

Transmission electron microscopy (TEM) analyses of Au NPs dispersed on a TEM grid were performed with a Cs-probe-corrected JEOL JEM ARM200F microscope at a primary beam energy of $200 \mathrm{keV}$ operated in scanning TEM (STEM) mode.

The amount of Au loading onto ZnO NRs was evaluated by Rutherford backscattering spectrometry (RBS, $2.0 \mathrm{MeV} \mathrm{He}^{+}$beam at normal incidence) with a $165^{\circ}$ backscattering angle using a 3.5 MV HVEE Singletron accelerator system (High Voltage Engineering Europa, The Netherlands). RBS spectra were analyzed using XRump software [37].

Photoluminescence (PL) measurements were performed by pumping at $\sim 0.7 \mathrm{~mW}$ the $325 \mathrm{~nm}(3.81 \mathrm{eV})$ line of a He-Cd laser chopped through an acousto-optic modulator at a frequency of $55 \mathrm{~Hz}$. The PL signal was analyzed using a single grating monochromator, detected with a Hamamatsu visible photomultiplier, and recorded with a lock-in amplifier using the acousto-optic modulator frequency as a reference. PL spectra were taken in air or vacuum within a cryostat $\left(\sim 10^{6}\right.$ mbar $)$ to ascertain the role of atmospheric $\mathrm{O}_{2}$. All PL spectra were converted by Jacobian transformation from wavelength to energy dispersion [38].

Cathodoluminescence (CL) measurements were performed using a Scanning Electron Microscope (Gemini field emission SEM Carl Zeiss SUPRA 25, FEG-SEM, Carl Zeiss Microscopy GmbH, Jena, Germany), equipped with a Gatan MonoCL3 CL spec- 
troscopy/imaging system. The beam energy was varied between 2 and $20 \mathrm{keV}$, providing different probe depths below the surface as determined by CASINO simulations [39]. All CL spectra were corrected for the overall detection response of the system.

Electrochemical measurements were carried out at room temperature by using a VersaSTAT 4 potentiostat (Princeton Applied Research, Oak Ridge, TN, USA) and a threeelectrode setup with a platinum counter electrode, a saturated calomel electrode (SCE) as reference electrode, and the samples as working electrodes. An amount of $0.5 \mathrm{M} \mathrm{Na}_{2} \mathrm{SO}_{4}$ (Sigma Aldrich, St. Louis, MO, USA, $\geq 85 \%$ ) was used as a supporting electrolyte. MottSchottky (M-S) analyses were conducted on bare and decorated ZnO NRs samples in the potential range $-1 \div 0 \mathrm{~V}$ vs. SCE, at $1000 \mathrm{~Hz}$ frequency.

A simulation of the band position of the semiconductor and the electric field on the surface of ZnO NRs induced by the metal decoration has been carried out by COMSOL Multiphysics ${ }^{\circledR}$ software (v.5.0, COMSOL Inc., Stockholm, Sweden) [40] (details in Supplementary Information).

\section{Results and Discussion}

The CBD grown $\mathrm{ZnO}$ nanorods are shown in Figure 1a-c. A uniform nanostructured film made of ZnO NRs grown onto Si can be seen in low magnification SEM image in Figure 1a. ZnO NRs present a width of approximately $100 \mathrm{~nm}$ and a length of $700 \mathrm{~nm}$ (Figure 1b,c). To decorate these ZnO NRs, we immersed this sample into the Au colloidal solution. The presence of Au nanoparticles within the colloidal solution produced with the modified Turkevich method was confirmed with UV-vis spectroscopy over two months (Figure S1). Both spectra showed a narrow and sharp peak (centered at around $530 \mathrm{~nm}$ ) which was a clear indication of the presence of stable NPs in colloidal form [35].
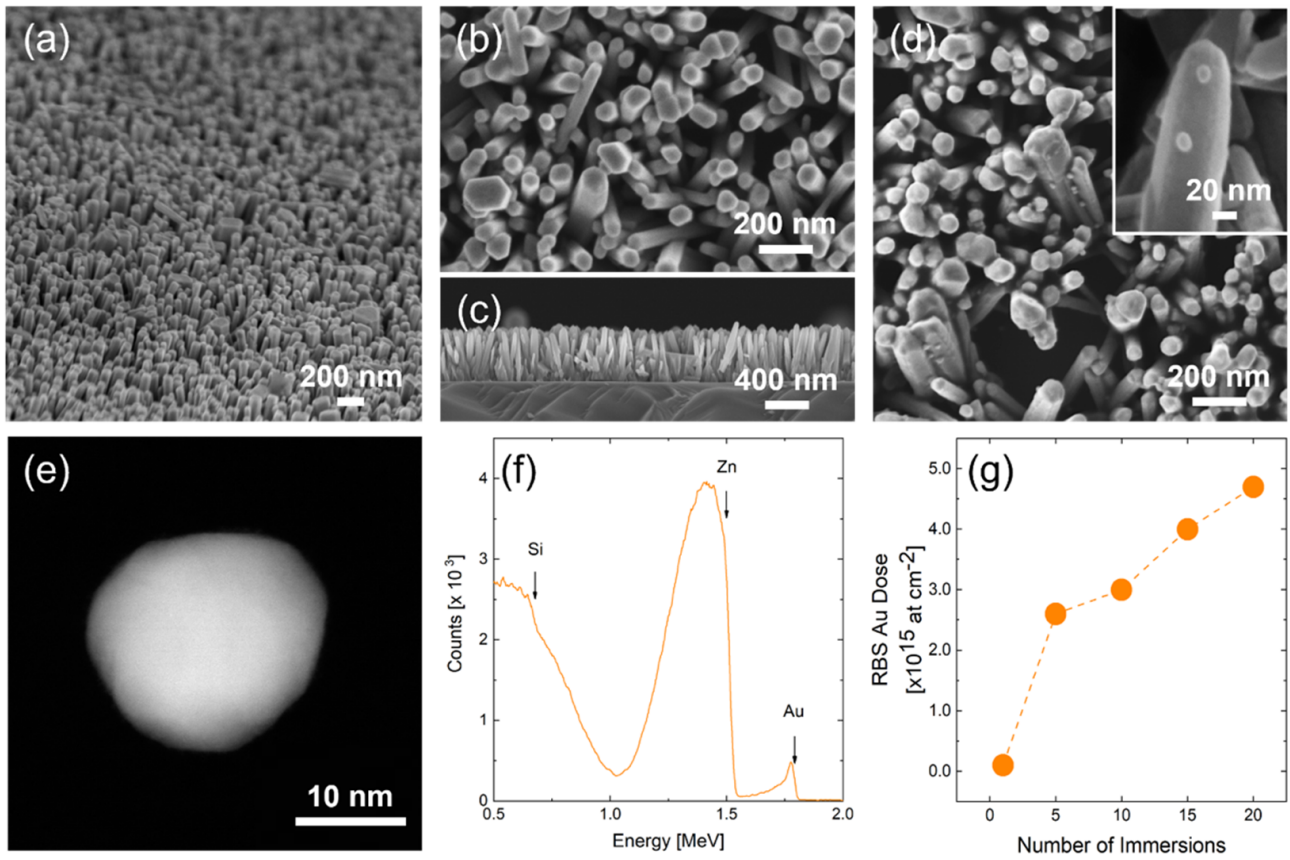

Figure 1. (a) Tilted SEM images of bare ZnO NRs; (b) magnified SEM image of ZnO NRs and (c) cross section SEM image of ZnO nanostructured film; (d) SEM images at different magnifications of $\mathrm{Au}_{20}-\mathrm{ZnO}$; (e) STEM image of a Au NP; (f) RBS spectrum of the $\mathrm{Au}_{20}-\mathrm{ZnO}$ sample; (g) variation of the Au loading on the surface of $\mathrm{ZnO} N R$ as a function of the number of immersions.

The effective decoration of ZnO NRs with metal NPs can be appreciated in Figure 1d, showing ZnO NRs with the surface densely decorated by Au NPs after 20 immersions (inset of Figure 1d). The NPs showed a reasonably uniform diameter of about $20 \pm 3 \mathrm{~nm}$, as measured by SEM images on more than 200 NPs dispersed on a flat Si substrate. A STEM picture of a representative Au nanoparticle is shown in Figure 1e, confirming the 
$20 \mathrm{~nm}$ size. Each nanoparticle has a rounded shape with some bumps due to the crystalline grains of which it is comprised (see Supplementary Information, Figure S2). RBS analyses (Figure 1f) confirmed the presence of a small amount of $\mathrm{Au}$ (peak at $1.8 \mathrm{MeV}$ ) and $\mathrm{Zn}$ (large peak at 1.0-1.5 MeV) onto Si (signal from 0.6 MeV downward), as expected. RBS was used to perform a quantitative measurement of Au after multiple immersion, since the $\mathrm{Au}$ amount is proportional to the Au peak in the spectrum [19]. Figure $1 \mathrm{~g}$ shows the variation in $\mathrm{Au}$ amounts with the number of immersions, showing a fairly linear increase from $1.0 \times 10^{14}$ at $\mathrm{cm}^{-2}$ (after 1 immersion) to $4.7 \times 10^{15}$ at cm $^{-2}$ (after 20 immersions). As expected, $\mathrm{Au}$ amounts on $\mathrm{ZnO}$ NRs increased with the number of immersions, allowing carefully monitoring of the extent of decoration. We verified that the size of Au NPs does not change with the number of immersions, confirming that the synthesis method produces highly stable suspension of Au NPs $[33,35]$. Our decoration method effectively covered the ZnO NRs surface with a varying density of Au NPs.

Au NP density cannot be ascertained by SEM analysis because of the rough surface and shadowing effect. Thus, the Au amount ( $D_{R B S}$, obtained by RBS [41]) was joined with Au NP diameter to evaluate the density $N$ of NPs decorating ZnO NRs, through the following relation:

$$
D_{R B S}=N \rho_{a t} V_{N P}
$$

where $\rho_{a t}$ is the Au atomic bulk density $\left(5.9 \times 10^{22}\right.$ at $\left.\mathrm{cm}^{-3}\right)$ and $V_{N P}$ is the volume of a single NP $\left(\mathrm{cm}^{3}\right)$ based on the measured size of NPs. The result of such an exercise shows that the NP density can be tuned from $1.0 \times 10^{9} \mathrm{NPs} \mathrm{cm}^{-2}$ to $4.5 \times 10^{10} \mathrm{NPs} \mathrm{cm}^{-2}$ (from 1 up to 20 immersions).

PL spectra were acquired for both bare and decorated NRs in vacuum and in air (Figure 2). All the emission spectra (Figure 2a) consisted of a UV region (2.7-3.5 eV) and a visible region (1.8-2.7 eV). Figure 2 reports the visible emission multiplied by a factor of 10 with respect to the UV emission. It is now well-documented that a UV peak arises from a very fast transition (timescale below 1 ns [42-49]) of free excitons from a donor state (FX-D) to valence band maximum (VBM) [50]. The visible emission is due to recombination between holes in VBM and electrons trapped at midgap levels induced by oxygen vacancy $\left(V_{O}\right)$ or zinc vacancy $\left(V_{Z n}\right)$ [20,50-53]. This process is much slower than that leading to UV emission, with characteristic times in the ns- $\mu$ s range $[42,44,47,49]$.

PL measurement in vacuum is aimed at disentangling the effect of atmospheric $\mathrm{O}_{2}$, as it is well-known that oxygen adsorption onto $\mathrm{ZnO}$ NRs modifies the energy bands at surface [51]. The visible PL is barely affected by gold decoration or $\mathrm{O}_{2}$ adsorption, but the UV radiative recombination of electron-holes in $\mathrm{ZnO}$ is clearly modified. The area of each peak in the PL spectra was related to the number of photons emitted in that energy range, so the ratio $\left(N_{v i s} / N_{U V}\right)$ between the areas of visible and UV peaks quantified how many photons were emitted in the visible range per each photon emitted in the UV range. Such a ratio indicates the relative probability of radiative recombination in the two channels, and its changes with surface condition are indicative of modification in the electron-hole recombination process. Figure $2 \mathrm{~b}$ displays $N_{v i s} / N_{U V}$ increasing with Au NP loading, both in air and in vacuum. In addition, this ratio, as measured in air, was always higher than in vacuum. It is worth noting that Au decoration in vacuum obtained the same effect $\left(N_{v i s} / N_{U V}\right.$ increase from 0.11 to 0.13 ) as $\mathrm{O}_{2}$ adsorption (without metal NPs). The largest visible-to-UV emission was obtained by joining the two effects on the $\mathrm{ZnO}$ surface $\left(\mathrm{O}_{2}\right.$ adsorption and Au decoration). This imbalance between $\mathrm{UV}$ and visible emission is later explained in terms of energy-band bending caused by nano-Schottky junction at the metal-semiconductor interface. 

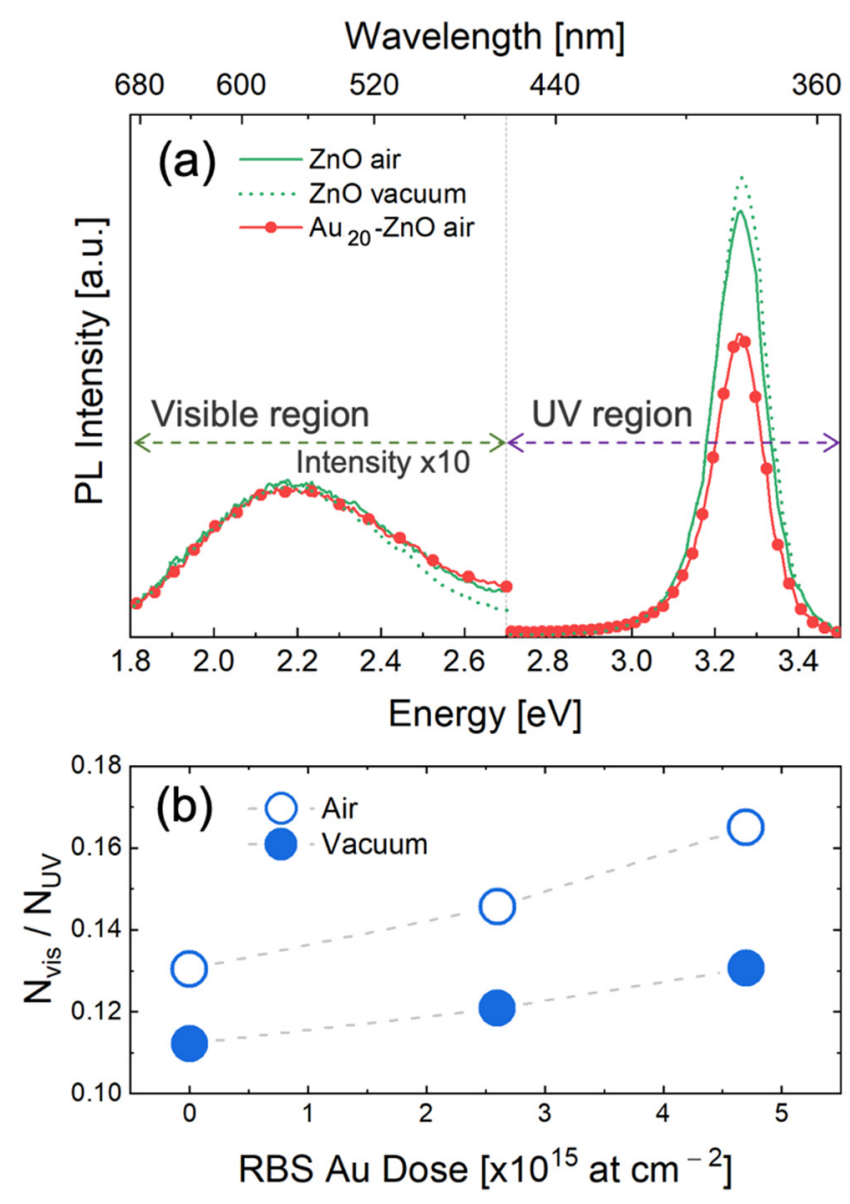

Figure 2. (a) PL spectra of bare $\mathrm{ZnO}$ (green continuous line) and $\mathrm{Au}_{20}-\mathrm{ZnO}$ (red and dotter line) in air, and bare $\mathrm{ZnO}$ in vacuum (green dotted line), with visible emission multiplied by a factor of 10 ; (b) ratio between the intensity of visible $\left(N_{v i s}\right)$ and UV emission $\left(N_{U V}\right)$ in air and in vacuum versus $\mathrm{Au}$ NP-decoration extent.

The experimental results reveal that $\mathrm{Au}$ NP decoration and $\mathrm{O}_{2}$ surface adsorption show a similar effect on the radiative recombination, as they: (i) reduce the UV emission and slightly increase the visible emission; (ii) produce a high energy tail in the visible emission spectrum.

To further investigate the effect of $\mathrm{ZnO}$ NRs decoration with $\mathrm{Au} N \mathrm{NP}$, CL analyses were carried out on bare $(\mathrm{ZnO})$ and decorated samples $\left(\mathrm{Au}_{20}-\mathrm{ZnO}\right)$. $\mathrm{CL}$ spectra were acquired at different electron beam energies $\left(E_{0}\right.$, varied in the range 2-20 keV) and different beam currents (using SEM aperture of 10, 30 and $60 \mu \mathrm{m}$ ). CL spectra for bare $\mathrm{ZnO}$ and $\mathrm{Au}_{20}-\mathrm{ZnO}$ at a beam energy of $10 \mathrm{keV}$ are reported in Figure 3a. The CL spectra showed the emission from two different peaks, a sharp UV peak and a broad visible region (as in PL analysis). For $\mathrm{Au}_{20}-\mathrm{ZnO}$ (red line in Figure 3), the absolute intensity of the two peaks significantly decreased compared to that of bare $\mathrm{ZnO}$, most likely because of the shadowing effect of the Au NPs in the decorated sample. 

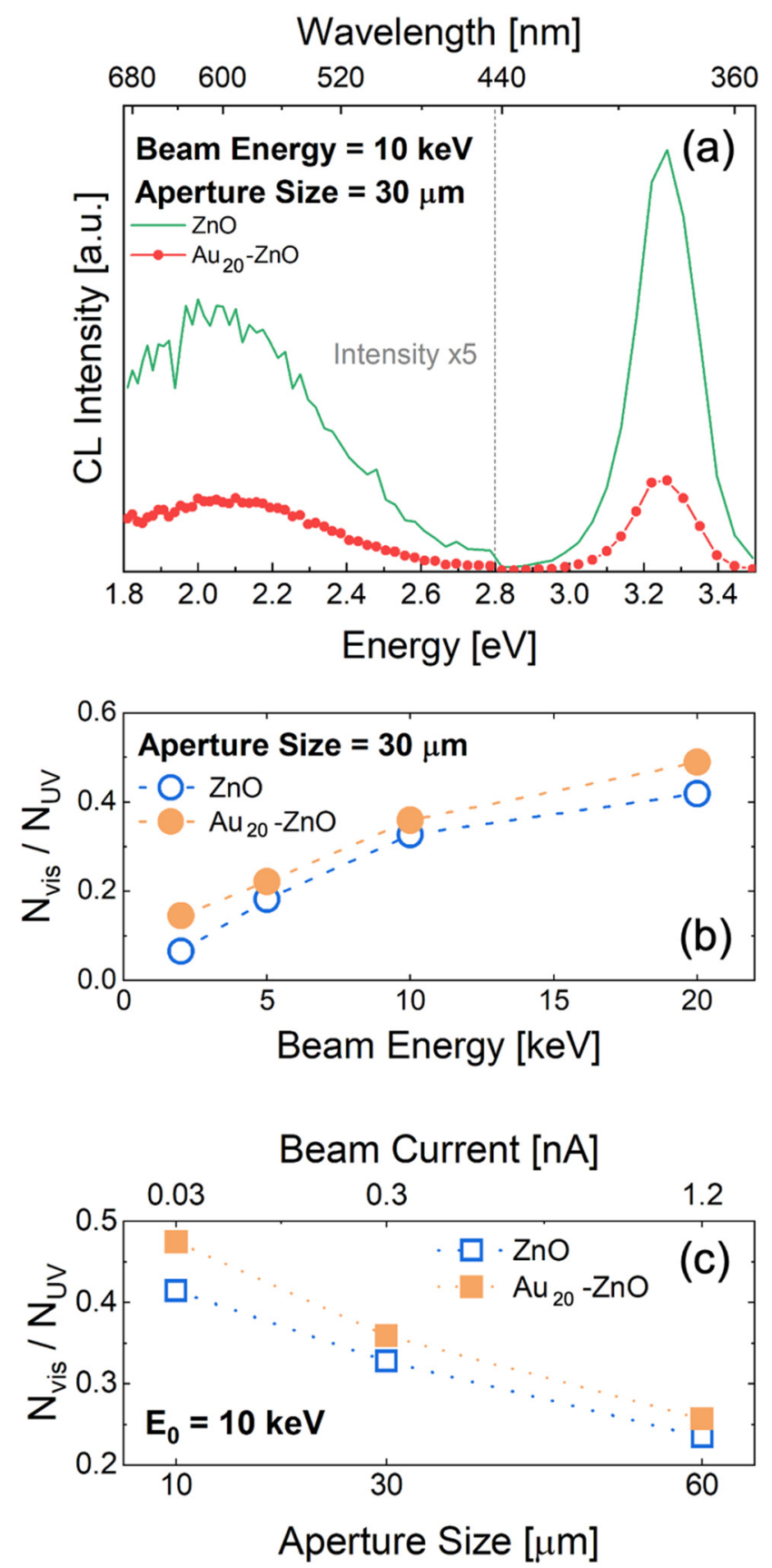

Figure 3. (a) $\mathrm{CL}$ spectra of bare $\mathrm{ZnO}$ (green) and $\mathrm{Au}_{20}-\mathrm{ZnO}$ (red), with visible emission multiplied by a factor of 5; ratio between the intensity of visible $\left(N_{v i s}\right)$ and $U V$ emission $\left(N_{U V}\right)$ as a function of the electron beam energy (b) and current (c).

CL spectra of bare $\mathrm{ZnO}$ acquired for different beam energies and currents are reported in the Supplementary Information (Figure S3). Figure $3 b, c$ show that the $N_{v i s} / N_{U V}$ ratio increased with beam energy and decreased with beam current. In PL as well as CL the presence of $\mathrm{Au}$ NPs gave a larger $N_{v i s} / N_{U V}$ ratio with respect to bare ZnO. As the beam energy increased, the probe depth also increased. The probe depths at different energies were simulated with Monte Carlo simulations through CASINO software [39,54-56] (Figure S4), ranging from a few tens of nanometers (at $2 \mathrm{keV}$ ) to 2 micrometers (at $20 \mathrm{keV}$ ). As a direct consequence, the generation of electron-hole pairs was diluted in a much larger volume, inducing a dramatic reduction of volumetric generation rate (Figure S4) by four orders of magnitude. This datum highlights that the $N_{v i s} / N_{U V}$ ratio increased at lower e-h pair 
generation rates. Figure $3 \mathrm{c}$ clearly confirms this trend, showing variation in the beam current without a change in probe depth. These results can be explained by considering the different timescales of the two radiative recombination processes. The slow process (leading to visible emission) became weaker at a high generation rate, most likely because the strong concentration gradient of electron-hole $(\mathrm{e}-\mathrm{h})$ pairs induced a significant diffusion which reduced the recombination on the long timescales.

In order to better understand the effect of Au decoration on energy bands and free carrier density, Mott-Schottky analysis was performed by immersing the bare and decorated $\mathrm{ZnO}$ NR sample in an aqueous solution of $\mathrm{Na}_{2} \mathrm{SO}_{4}$. Even if a liquid-semiconductor interface is now tested, we wish to extract information on the Au NPs decoration effects. $\mathrm{ZnO}$ and $\mathrm{Au}_{20}-\mathrm{ZnO}$ samples were characterized by measuring their capacitance as a function of electrode potential [57-62], and a typical result is shown in the Mott-Schottky plot $\left(C^{-2}\right.$ vs. $E$ ) in Figure 4. The flat band potential $E_{F B}$ and the donor density $N_{D}$ can be obtained from the linear part of the plot as intercept with $x$-axis and slope, respectively (see Supplementary Information for details) [57-60,62-65]. The plot appears to have a linear section in the potential range $-0.2 \div-0.45 \mathrm{~V}$ vs. SCE in the case of $\mathrm{ZnO}$, and $-0.2 \div-0.6 \mathrm{~V}$ vs. SCE for $\mathrm{Au}_{20}-\mathrm{ZnO}$ sample. The flat band potentials obtained were $-0.68 \mathrm{~V}$ and $-0.85 \mathrm{~V}$ vs. SCE for $\mathrm{ZnO}$ and $\mathrm{Au}_{20}-\mathrm{ZnO}$, respectively. Concerning donor concentration, from Equation (S5), we found values of $3.2 \times 10^{17} \mathrm{~cm}^{-3}$ and $2.0 \times 10^{16} \mathrm{~cm}^{-3}$ for bare and decorated samples, respectively. The flat band potential gave an indication of the band bending at the liquid-semiconductor interface at equilibrium, and here we observe that such a bending was almost $0.2 \mathrm{eV}$ greater in $\mathrm{Au}_{20}-\mathrm{ZnO}$. This was most likely due to the Au NP decoration. On the other hand, the reduction by one order of magnitude in the donor concentration in $\mathrm{Au}_{20}-\mathrm{ZnO}$ confirmed that $\mathrm{Au} \mathrm{NP}$ decoration effectively depleted the free carriers on the surfaces of the $\mathrm{ZnO}$ NRs.

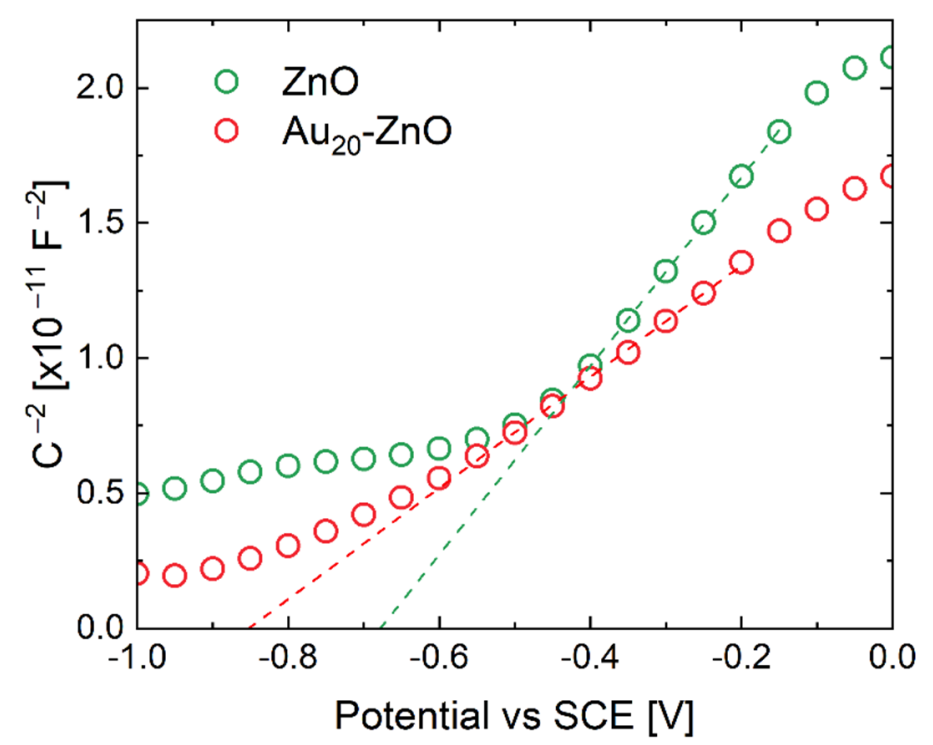

Figure 4. Mott-Schottky plot of $\mathrm{ZnO}$ and $\mathrm{Au}_{20}-\mathrm{ZnO}$ in $0.5 \mathrm{M} \mathrm{Na}_{2} \mathrm{SO}_{4}$ (dashed lines represent the fits to linear regions).

\section{Modeling the Au NP Decoration Effect}

$\mathrm{Au} \mathrm{NP}$-decoration clearly affects the electronic energy band at $\mathrm{ZnO}$, as largely shown in the previous section. We now attempt to quantify such an effect, investigating the band bending at the metal-semiconductor interface through a multiphysics approach.

To visualize the band modification in ZnO NRs decorated with metal NPs, COMSOL [40] simulations were performed assuming a single Au circular dot ( $20 \mathrm{~nm}$ in size) placed onto $\mathrm{ZnO}$ in a vacuum ambient (see Figure S5 for a scheme of simulation). Band bending occurs at the metal-semiconductor junction because of differing work functions. 
$\mathrm{Au}$ has a higher work function $\left(\Phi_{\mathrm{Au}}=4.8 \mathrm{eV}\right.$ [66]) than that of $\mathrm{ZnO}\left(\Phi_{\mathrm{B}}=4.2 \mathrm{eV}[67]\right)$, leading to a potential barrier for electrons and to a significant upwards bending of $\mathrm{ZnO}$ conduction and valence bands at the metal-semiconductor interface. The energy map of the conduction band minimum (CBM) as a function of depth and distance from the NP center is reported in Figure $5 \mathrm{a}$. The simulation disregarded any surface defects or temperature dependence. The upward bending of the CBM surmounted $0.6 \mathrm{eV}$ beneath the Au NP center and extended almost $20 \mathrm{~nm}$ within the $\mathrm{ZnO}$ material. As a consequence, electron population in the conduction band was significantly affected. Moreover, an extensive electric field arise under the $\mathrm{Au} \mathrm{NP}$, pointing $\mathrm{Au}$. The 2D map of the electric field at the $\mathrm{ZnO}$ surface below a circular Au dot is shown in Figure 5b, showing intensity as high as $10^{8} \mathrm{~V} \mathrm{~m}^{-1}$ with a characteristic halo effect beneath the Au NP circumference. The electric field is proportional to the spatial derivative of the CBM energy; thus, the highest electric field is found close to the Au NP edges, creating this distinctive halo. Such a strong and localized electric field caused by Au decoration is extremely effective in modifying the band profile and carrier density close to the surface. Moreover, the halo effect may be responsible for the catalytic effect at $\mathrm{ZnO}$ surface sites close to Au NP edges.
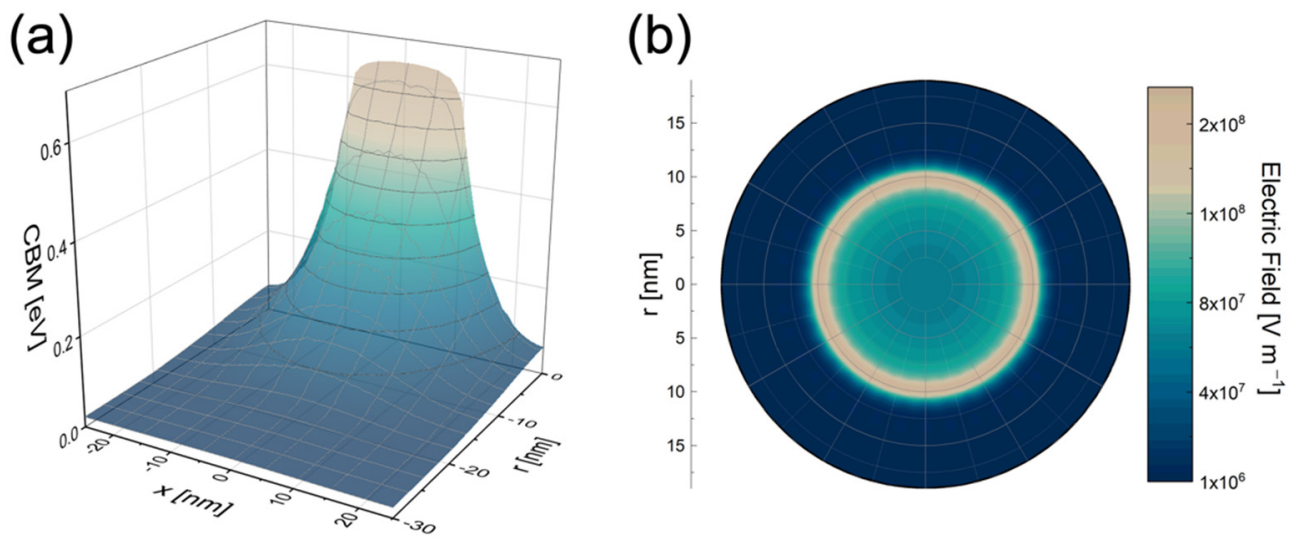

Figure 5. COMSOL simulations at the interface between Au and ZnO NR. (a) 3D plot showing CBM energy and (b) electric field map in $\mathrm{ZnO} 5 \mathrm{~nm}$ below a circular Au dot.

To understand the PL and CL data of ZnO NRs decorated with Au NPs, the radiative mechanism in $\mathrm{ZnO}$ NRs must be detailed. As already stated, UV emission is a rapid process occurring a fraction of a ns after e-h generation, while visible emission at mid-gap levels is a radiative recombination of e-h much slower than that causing UV emission [42]. It has already been demonstrated that these levels are below the Fermi level $[24,68,69]$. Thus, UV emission is expected to be affected by band bending to a far greater degree than visible emission, as the former is related to shallow levels whose population largely depends on Fermi level position [19]. The presence of a large electric field caused by $\mathrm{Au}$ NP decoration (Figure $5 \mathrm{~b}$ ) could very effectively promote separation of generated charge carriers, thus reducing the rapid e-h recombination. This separation could explain the increase of $N_{v i s} / N_{U V}$ ratio observed in the decorated samples (both in PL and in CL analyses).

\section{Conclusions}

In conclusion, this study reports the investigation of a simple procedure for $\mathrm{ZnO} N R \mathrm{~s}$ decoration with $\mathrm{Au}$ NPs, in which the effects on the position and population of electronic energy bands of $\mathrm{ZnO}$ were discussed and modelled. Surface decoration with $20 \mathrm{~nm} \mathrm{Au}$ NPs was achieved by multiple immersion in a colloidal solution, leading to NP density up to $4.5 \times 10^{10} \mathrm{NPs} \mathrm{cm}^{-2}$. Au decoration significantly affected the radiative emission of $\mathrm{ZnO}$ to different extents in the $\mathrm{UV}$ and visible emission processes. The Au decoration significantly reduced the UV radiative emission in comparison to the visible emission. Such 
evidence is attributed to a noteworthy upwards band bending caused by the nano-Schottky junction formed at the $\mathrm{Au}-\mathrm{ZnO}$ interface. A strong electric field (up to $10^{8} \mathrm{~V} \mathrm{~m}^{-1}$ ) at $\mathrm{ZnO}$ surface results from multiphysics simulation, with a distinctive halo effect beneath the $\mathrm{Au}$ NP edges. The effect in photo- and cathodoluminescence analyses is discussed in terms of enhanced separation of generated e-h pairs.

Supplementary Materials: The following are available online at https:/ /www.mdpi.com/article/10 $.3390 /$ nano11102718/s1, Figure S1: Absorbance spectrum of Au NP solution as prepared and after 2 months; Figure S2: STEM micrograph and high magnification insets of an isolated Au NP; Figure S3: CL spectra of bare $\mathrm{ZnO}$ at different electron beam energies; Figure S4: (a) CASINO simulation of the probe depth of the electron beam at different beam energies; (b) e-h generation rate (calculated from Equation (S3)); Figure S5: 2D COMSOL simulation of the electric field of a single ZnO NR in presence of a Au NP on its surface.

Author Contributions: L.B.: Investigation, simulations, data curation, visualization, writing, original draft preparation, reviewing and editing. V.S.: Investigation and reviewing. M.S.: Investigation and reviewing. G.F.: Methodology, investigation and reviewing. F.P.: Supervision. S.M.: Supervision, conceptualization, methodology, investigation, reviewing and editing. All authors have read and agreed to the published version of the manuscript.

Funding: This work was supported by programma ricerca di Ateneo UNICT 2020-22 linea 2 PIA.CE.RI "NaTI4Smart Sviluppo di NAnomateriali e Tecnologie Innovative per Smart detection", by PRIN 2017 "CLEAN-Valorizing Sustainable Plastics through a CLEver use of NANoparticles" 20174FSRZS_003 and by "PON MIUR ADAS +" (ARS01_00459).

Institutional Review Board Statement: Not applicable.

Informed Consent Statement: Not applicable.

Data Availability Statement: The data presented in this study are available on request from the corresponding author.

Acknowledgments: The authors wish to thank G. Pantè and S. Tatì (CNR-IMM Catania, Italy) for technical support.

Conflicts of Interest: The authors declare no conflict of interest.

\section{References}

1. Djurišić, A.B.; Leung, Y.H. Optical Properties of ZnO Nanostructures. Small 2006, 2, 944-961. [CrossRef]

2. Wang, Z.L. Nanostructures of zinc oxide. Mater. Today 2004, 7, 26-33. [CrossRef]

3. Battaglia, C.; Escarré, J.; Söderström, K.; Charrière, M.; Despeisse, M.; Haug, F.-J.; Ballif, C. Nanomoulding of transparent zinc oxide electrodes for efficient light trapping in solar cells. Nat. Photon 2011, 5, 535-538. [CrossRef]

4. Hu, L.; Yan, J.; Liao, M.; Xiang, H.; Gong, X.; Zhang, L.; Fang, X. An Optimized Ultraviolet-A Light Photodetector with Wide-Range Photoresponse Based on ZnS/ZnO Biaxial Nanobelt. Adv. Mater. 2012, 24, 2305-2309. [CrossRef] [PubMed]

5. Sergent, S.; Takiguchi, M.; Tsuchizawa, T.; Yokoo, A.; Taniyama, H.; Kuramochi, E.; Notomi, M. Nanomanipulating and Tuning Ultraviolet ZnO-Nanowire-Induced Photonic Crystal Nanocavities. ACS Photon 2017, 4, 1040-1047. [CrossRef]

6. Sergent, S.; Takiguchi, M.; Tsuchizawa, T.; Taniyama, H.; Notomi, M. ZnO-Nanowire-Induced Nanocavities in Photonic Crystal Disks. ACS Photon 2019, 6, 1132-1138. [CrossRef]

7. Akermi, M.; Jaballah, N.; Alarifi, I.M.; Rahimi-Gorji, M.; Ben Chaabane, R.; Ben Ouada, H.; Majdoub, M. Synthesis and characterization of a novel hydride polymer P-DSBT/ZnO nano-composite for optoelectronic applications. J. Mol. Liq. 2019, 287, 110963. [CrossRef]

8. Zhou, J.; Nomenyo, K.; Cesar, C.C.; Lusson, A.; Schwartzberg, A.; Yen, C.-C.; Woon, W.-Y.; Lerondel, G. Giant defect emission enhancement from $\mathrm{ZnO}$ nanowires through desulfurization process. Sci. Rep. 2020, 10, 4237. [CrossRef]

9. Ramya, M.; Nideep, T.K.; Nampoori, V.P.N.; Kailasnath, M. Solvent assisted evolution and growth mechanism of zero to three dimensional $\mathrm{ZnO}$ nanostructures for dye sensitized solar cell applications. Sci. Rep. 2021, 11, 1-14. [CrossRef]

10. Mehmood, M.; Ali, S.M.; Ramay, S.M.; Alkhuraiji, T.S. Au/ZnO hybrid nanocomposites and their optical and photocatalytic properties. Appl. Phys. A 2020, 126, 1-14. [CrossRef]

11. Nguyen, T.H.; Do, T.A.T.; Giang, H.T.; Ho, T.G.; Pham, Q.N.; Man, M.T. Effect of metal-support couplings on the photocatalytic performance of Au-decorated ZnO nanorods. J. Mater. Sci. Mater. Electron. 2020, 31, 14946-14952. [CrossRef]

12. Ponnuvelu, D.V.; Dhakshinamoorthy, J.; Prasad, A.K.; Dhara, S.K.; Kamruddin, M.; Pullithadathil, B. Geometrically Controlled Au-Decorated ZnO Heterojunction Nanostructures for NO2 Detection. ACS Appl. Nano Mater. 2020, 3, 5898-5909. [CrossRef] 
13. Wang, J.; Fan, S.; Xia, Y.; Yang, C.; Komarneni, S. Room-temperature gas sensors based on ZnO nanorod/Au hybrids: Visiblelight-modulated dual selectivity to NO2 and NH3. J. Hazard. Mater. 2020, 381, 120919. [CrossRef]

14. Laskowski, F.; Oener, S.Z.; Nellist, M.R.; Gordon, A.M.; Bain, D.C.; Fehrs, J.L.; Boettcher, S.W. Nanoscale semiconductor/catalyst interfaces in photoelectrochemistry. Nat. Mater. 2019, 19, 69-76. [CrossRef] [PubMed]

15. Chen, T.; Xing, G.Z.; Zhang, Z.; Chen, H.Y.; Wu, T. Tailoring the photoluminescence of ZnO nanowires using Au nanoparticles. Nanotechnology 2008, 19, 435711. [CrossRef] [PubMed]

16. Bora, T.; Myint, M.T.Z.; Al-Harthi, S.H.; Dutta, J. Role of surface defects on visible light enabled plasmonic photocatalysis in Au-ZnO nanocatalysts. RSC Adv. 2015, 5, 96670-96680. [CrossRef]

17. Raji, R.; Gopchandran, K. Plasmonic photocatalytic activity of $\mathrm{ZnO}$ :Au nanostructures: Tailoring the plasmon absorption and interfacial charge transfer mechanism. J. Hazard. Mater. 2019, 368, 345-357. [CrossRef]

18. Shahine, I.; Jradi, S.; Beydoun, N.; Gaumet, J.-J.; Akil, S. Plasmon-Enhanced Photoluminescence and Photocatalysis Reactions in Metal-Semiconductor Nanomaterials: UV-Generated Hot Electron in Gold-Zinc Oxide. ChemPhotoChem 2019, 4, 181-194. [CrossRef]

19. Bahariqushchi, R.; Cosentino, S.; Scuderi, M.; Dumons, E.; Tran-Huu-Hue, L.P.; Strano, V.; Grandjean, D.; Lievens, P.; PoulinVittrant, G.; Spinella, C.; et al. Free carrier enhanced depletion in $\mathrm{ZnO}$ nanorods decorated with bimetallic AuPt nanoclusters. Nanoscale 2020, 12, 19213-19222. [CrossRef] [PubMed]

20. Hsu, N.E.; Hung, W.K.; Chen, Y.F. Origin of defect emission identified by polarized luminescence from aligned ZnO nanorods. J. Appl. Phys. 2004, 96, 4671. [CrossRef]

21. Shan, W.; Walukiewicz, W.; Ager, J.; Yu, K.M.; Yuan, H.B.; Xin, H.P.; Cantwell, G.; Song, J.J. Nature of room-temperature photoluminescence in ZnO. Appl. Phys. Lett. 2005, 86, 191911. [CrossRef]

22. Djurišić, A.B.; Leung, Y.H.; Tam, K.H.; Ding, L.; Ge, W.K.; Chen, H.Y.; Gwo, S. Green, yellow, and orange defect emission from ZnO nanostructures: Influence of excitation wavelength. Appl. Phys. Lett. 2006, 88, 103107. [CrossRef]

23. Tam, K.H.; Cheung, C.K.; Leung, Y.H.; Djurišić, A.B.; Ling, C.C.; Beling, C.D.; Fung, S.; Kwok, W.M.; Chan, W.K.; Phillips, D.L.; et al. Defects in ZnO Nanorods Prepared by a Hydrothermal Method. J. Phys. Chem. B 2006, 110, 20865-20871. [CrossRef] [PubMed]

24. Wang, D.; Reynolds, N. Photoluminescence of Zinc Oxide Nanowires: The Effect of Surface Band Bending. ISRN Condens. Matter Phys. 2012, 2012, 1-6. [CrossRef]

25. Fabbri, F.; Villani, M.; Catellani, A.; Calzolari, A.; Cicero, G.; Calestani, G.; Zappettini, A.; Dierre, B.; Sekiguchi, T.; Salviati, G. Zn vacancy induced green luminescence on non-polar surfaces in ZnO nanostructures. Sci. Rep. 2015, 4, 5158. [CrossRef] [PubMed]

26. Kumar, V.; Ntwaeaborwa, O.M.; Soga, T.; Dutta, V.; Swart, H.C. Rare Earth Doped Zinc Oxide Nanophosphor Powder: A Future Material for Solid State Lighting and Solar Cells. ACS Photon 2017, 4, 2613-2637. [CrossRef]

27. Fiedler, S.; Lem, L.O.L.C.; Ton-That, C.; Phillips, M.R. The role of surface depletion layer effects on the enhancement of the UV emission in $\mathrm{ZnO}$ induced by a nanostructured Al surface coating. Appl. Surf. Sci. 2019, 504, 144409. [CrossRef]

28. Peralta, M.D.L.R.; Pal, U.; Zeferino, R.S. Photoluminescence (PL) Quenching and Enhanced Photocatalytic Activity of AuDecorated ZnO Nanorods Fabricated through Microwave-Assisted Chemical Synthesis. ACS Appl. Mater. Interfaces 2012, 4, 4807-4816. [CrossRef]

29. Park, S.; Mun, Y.; An, S.; Lee, W.I.; Lee, C. Enhanced photoluminescence of Au-functionalized ZnO nanorods annealed in a hydrogen atmosphere. J. Lumin 2014, 147, 5-8. [CrossRef]

30. Udawatte, N.; Lee, M.; Kim, J.; Lee, D. Well-Defined Au/ZnO Nanoparticle Composites Exhibiting Enhanced Photocatalytic Activities. ACS Appl. Mater. Interfaces 2011, 3, 4531-4538. [CrossRef]

31. Rai, P.; Kim, Y.-S.; Song, H.-M.; Song, M.-K.; Yu, Y.-T. The role of gold catalyst on the sensing behavior of ZnO nanorods for CO and $\mathrm{NO}_{2}$ gases. Sens. Actuators B Chem. 2012, 165, 133-142. [CrossRef]

32. Strano, V.; Urso, R.G.; Scuderi, M.; Iwu, K.O.; Simone, F.; Ciliberto, E.; Spinella, C.; Mirabella, S. Double Role of HMTA in ZnO Nanorods Grown by Chemical Bath Deposition. J. Phys. Chem. C 2014, 118, 28189-28195. [CrossRef]

33. Turkevich, J.; Stevenson, P.C.; Hillier, J. A study of the nucleation and growth processes in the synthesis of colloidal gold. Discuss. Faraday Soc. 1951, 11, 55-75. [CrossRef]

34. Frens, G. Controlled Nucleation for the Regulation of the Particle Size in Monodisperse Gold Suspensions. Nat. Phys. Sci. 1973, 241, 20-22. [CrossRef]

35. Tyagi, H.; Kushwaha, A.K.; Kumar, A.; Aslam, M. A Facile pH Controlled Citrate-Based Reduction Method for Gold Nanoparticle Synthesis at Room Temperature. Nanoscale Res. Lett. 2016, 11, 1-11. [CrossRef]

36. ImageJ. Available online: www.imagej.nih.gov (accessed on 1 February 2021).

37. Thompson, M. Xrump. Available online: www.genplot.com (accessed on 1 February 2021).

38. Mooney, J.; Kambhampati, P. Get the basics right: Jacobian conversion of wavelength and energy scales for quantitative analysis of emission spectra. J. Phys. Chem. Lett. 2013, 4, 3316-3318. [CrossRef]

39. Drouin, D.; Couture, A.R.; Joly, D.; Tastet, X.; Aimez, V.; Gauvin, R. CASINO V2.42-A Fast and Easy-to-use Modeling Tool for Scanning Electron Microscopy and Microanalysis Users. Scanning 2007, 29, 92-101. [CrossRef] [PubMed]

40. COMSOL Multiphysics ${ }^{\circledR}$ v. 5.3. COMSOL AB, Stockholm, Sweden. Available online: http://www.comsol.com (accessed on 1 February 2021). 
41. Feldman, L.C.; Mayer, J.W.; Grasserbauer, M. Fundamentals of surface and thin film analysis. Anal. Chim. Acta 1987, $199,288$. [CrossRef]

42. Studenikin, S.A.; Cocivera, M. Time-resolved luminescence and photoconductivity of polycrystalline ZnO films. J. Appl. Phys. 2002, 91, 5060-5065. [CrossRef]

43. Hong, S.; Joo, T.; Park, W.I.; Jun, Y.H.; Yi, G.-C. Time-resolved photoluminescence of the size-controlled ZnO nanorods. Appl. Phys. Lett. 2003, 83, 4157. [CrossRef]

44. Kwok, W.-M.; Djurišić, A.B.; Leung, Y.H.; Chan, W.K.; Phillips, D.L. Time-resolved photoluminescence from ZnO nanostructures. Appl. Phys. Lett. 2005, 87, 223111. [CrossRef]

45. Zhang, X.H.; Chua, S.J.; Yong, A.M.; Yang, H.Y.; Lau, S.P.; Yu, S.F.; Sun, X.W.; Miao, L.; Tanemura, M.; Tanemura, S. Exciton radiative lifetime in $\mathrm{ZnO}$ nanorods fabricated by vapor phase transport method. Appl. Phys. Lett. 2007, 90, 013107. [CrossRef]

46. Zhao, Q.; Yang, L.L.; Willander, M.; Sernelius, B.; Holtz, P.-O. Surface recombination in ZnO nanorods grown by chemical bath deposition. J. Appl. Phys. 2008, 104, 073526. [CrossRef]

47. Klason, P.; Børseth, T.M.; Zhao, Q.X.; Svensson, B.G.; Kuznetsov, A.Y.; Bergman, P.J.; Willander, M. Temperature dependence and decay times of zinc and oxygen vacancy related photoluminescence bands in zinc oxide. Solid State Commun. 2008, 145, 321-326. [CrossRef]

48. Layek, A.; Manna, B.; Chowdhury, A. Carrier recombination dynamics through defect states of ZnO nanocrystals: From nanoparticles to nanorods. Chem. Phys. Lett. 2012, 539-540, 133-138. [CrossRef]

49. Biroju, R.K.; Giri, P.K. Strong visible and near infrared photoluminescence from ZnO nanorods/nanowires grown on single layer graphene studied using sub-band gap excitation. J. Appl. Phys. 2017, 122, 044302. [CrossRef]

50. Barbagiovanni, E.G.; Reitano, R.; Franzò, G.; Strano, V.; Terrasi, A.; Mirabella, S. Radiative mechanism and surface modification of four visible deep level defect states in $\mathrm{ZnO}$ nanorods. Nanoscale 2016, 8, 995-1006. [CrossRef]

51. Barbagiovanni, E.G.; Strano, V.; Franzò, G.; Crupi, I.; Mirabella, S. Photoluminescence transient study of surface defects in ZnO nanorods grown by chemical bath deposition. Appl. Phys. Lett. 2015, 106, 093108. [CrossRef]

52. Brillson, L.; Mosbacker, H.; Hetzer, M.; Strzhemechny, Y.; Look, D.; Cantwell, G.; Zhang, J.; Song, J. Surface and near-surface passivation, chemical reaction, and Schottky barrier formation at ZnO surfaces and interfaces. Appl. Surf. Sci. 2008, 254, 8000-8004. [CrossRef]

53. Barbagiovanni, E.G.; Strano, V.; Franzò, G.; Reitano, R.; Dahiya, A.S.; Poulin-Vittrant, G.; Alquier, D.; Mirabella, S. Universal model for defect-related visible luminescence in ZnO nanorods. RSC Adv. 2016, 6, 73170-73175. [CrossRef]

54. Brillson, L.J. Applications of depth-resolved cathodoluminescence spectroscopy. J. Phys. D Appl. Phys. 2012, 45, 183001. [CrossRef]

55. Ye, J.D.; Zhao, H.; Liu, W.; Gu, S.L.; Zhang, R.; Zheng, Y.D.; Tan, S.T.; Sun, X.W.; Lo, G.Q.; Teo, K.L. Theoretical and experimental depth-resolved cathodoluminescence microanalysis of excitonic emission from ZnO epilayers. Appl. Phys. Lett. 2008, $92,131914$. [CrossRef]

56. Toth, M.; Phillips, M.R. Monte Carlo modeling of cathodoluminescence generation using electron energy loss curves. Scanning 1998, 20, 425-432. [CrossRef]

57. Bott, A.W. Electrochemistry of Semiconductors. Curr. Sep. 1998, 17, 3, ISSN 0891-0006.

58. Beranek, R. (Photo)electrochemical Methods for the Determination of the Band Edge Positions of TiO2-Based Nanomaterials. Adv. Phys. Chem. 2011, 2011, 1-20. [CrossRef]

59. Fabregat-Santiago, F.; Garcia-Belmonte, G.; Bisquert, J.; Bogdanoff, P.; Zaban, A. Mott-Schottky Analysis of Nanoporous Semiconductor Electrodes in Dielectric State Deposited on $\mathrm{SnO}_{2}(\mathrm{~F})$ Conducting Substrates. J. Electrochem. Soc. 2003, 150, E293-E298. [CrossRef]

60. Hankin, A.; Bedoya-Lora, F.E.; Alexander, J.C.; Regoutz, A.; Kelsall, G.H. Flat band potential determination: Avoiding the pitfalls. J. Mater. Chem. A 2019, 7, 26162-26176. [CrossRef]

61. Memming, R. Semiconductor Electrochemistry; Wiley \& Sons: Hoboken, NJ, USA, 2015.

62. Scholz, F. Electroanalytical Methods: Guide to Experiments and Applications; Springer: Berlin/Heidelberg, Germany, 2010; ISBN 9783642029141.

63. Xu, P.; Milstein, T.J.; Mallouk, T.E. Flat-Band Potentials of Molecularly Thin Metal Oxide Nanosheets. ACS Appl. Mater. Interfaces 2016, 8, 11539-11547. [CrossRef]

64. Gelderman, K.; Lee, L.; Donne, S. Flat-Band Potential of a Semiconductor: Using the Mott-Schottky Equation. J. Chem. Educ. 2007, 84, 685. [CrossRef]

65. Darowicki, K.; Krakowiak, S.; Ślepski, P. Selection of measurement frequency in Mott-Schottky analysis of passive layer on nickel. Electrochim. Acta 2006, 51, 2204-2208. [CrossRef]

66. Henry, M.; Fanet, H. Physique des Semiconducteurs et des Composants Électroniques; Dunod: Malakoff, France, 2019.

67. Gutmann, S.; Conrad, M.; Wolak, M.A.; Beerbom, M.M.; Schlaf, R. Work function measurements on nano-crystalline zinc oxide surfaces. J. Appl. Phys. 2012, 111, 123710. [CrossRef]

68. Ahn, C.H.; Kim, Y.Y.; Kim, D.C.; Mohanta, S.K.; Cho, H.K. A comparative analysis of deep level emission in ZnO layers deposited by various methods. J. Appl. Phys. 2009, 105, 013502. [CrossRef]

69. Janotti, A.; Van de Walle, C.G. Native point defects in ZnO. Phys. Rev. B 2007, 76, 165202. [CrossRef] 